\title{
Effect of Macroporous Support Particles on Cell Immobilization, Mass Transfer and Rheology in a Stirred Cultivation of Aspergillus oryzae Using a Swingstir ${ }^{\circledR}$ Mixer
}

\author{
Narges Ghobadi, Chiaki Ogino, Naoto Ohmura
}

\begin{abstract}
Immobilization of filamentous fungi via bioprocessing is a popular way to avoid mechanical damage to cells while increasing enzymatic activity. Passive immobilization is an efficient because chemical additives are not used during the immobilization process. In this study, passive immobilization of Aspergillus oryzae was performed in a stirred tank via a flexible agitator to improve the oxygen mass transfer and rheology while increasing the enzymatic activity. To elucidate the effect of porous biomass support particles on these factors, two particles with different sizes and populations were tested in separate batch cultivations. Results showed that one of the advantages of fungal immobilization is the prevention of a high rate of glucose consumption during a submerged fermentation process. Decreasing the size of the biomass support particle increased the shear-thinning behaviour of fluid. We also determined the optimal number of particles needed to produce the largest final amounts of immobilized biomass and enzyme activity.
\end{abstract}

Index Terms- Aspergillus oryzae, fermentation, immobilization, porous particle

\section{INTRODUCTION}

Recently, the use of cell immobilization of fungal cells has increased because the fungi can produce commercial compounds such as organic acid, enzymes, antibiotics and steroids [1]. One of the disadvantages of fermentation of non-immobilized fungal biomass is exposure to shear stress. Immobilizing the cells either inside the particles or on the particle surface, is a safe and easy way to protect the biomass and improve the fungal activity [2]. Also, immobilization of biomass can be achieved in repeatable systems[3], [4].

More studies are showing that passive immobilization [5] provides a natural method for immobilizing cells without the addition of chemicals, without the aseptic handling of biomass support particles (BSPs), and without a significant reduction in the mass transfer rate within BSPs. In a previous study, Rhizopus species were immobilized within a dense film of pellets near the surface of BSPs in a polyurethane foam [6], [7]. In another study, acetone-dried cells of $R$. chinensis were immobilized within polyurethane foam

Narges Ghobadi, Graduate School of Engineering, Department of Chemical Science and Engineering, Kobe University, Kobe, Japan

Chiaki Ogino, Graduate School of Engineering, Department of Chemical Science and Engineering, Kobe University, Kobe, Japan

Naoto Ohmura, Graduate School of Engineering, Department of Chemical Science and Engineering, Kobe University, Kobe, Japan particles (BSP) that could be used directly as a whole cell biocatalyst [6].

In another study, the addition of micro-particles (e.g., aluminum oxide, magnesium silicate, and titanium silicate oxide) to the fermentation culture [8]-[10] caused the formation of active mycelia via physical interactions that included the collision-induced disruption of conidia aggregates and a hindrance of new spore-to-spore interactions at the beginning of cultivation. In that study, immobilization of the fungal cells on supports allowed an easier liquid -solid separation and avoided clogging phenomena [2].

Consequently, one method for improving the difficulties in mass transfer and diffusion of substrate material is to immobilize cells either into or on the surface of thin films. Another possibility is to immobilize the cells in a fibrous matrix, which is attained by natural attachment or crosslinking to fibers. The problem lies in anchoring the microorganisms firmly to the matrix walls. Macroporous spongy carriers (like polyurethane or cellulose foams) have been used to avoid microorganism adherence and substrate penetration in a culture. There is, however, a need to match the shape and size of the cell presents additional challenges [11]. Hama et al., 2015, [12] confirmed that the morphology of A.oryzae in submerged fermentation can be controlled.

The current study was focused on investigating the possibility of enhancing cell immobilization by using a Swingstir $^{\circledR}$ (Kobelco Eco-Solutions, Co., Ltd. Kobe, Japan) and determining the effect to enzyme activity, oxygen mass transfer, and the rheology of a cell culture of recombinant $A$. oryzae. It was hoped that passive immobilization of the cells of A. oryzae in a stirred tank by such a flexible agitator could improve the oxygen mass transfer and decrease the damage due to mechanical stress to the filamentous fungi. Two important operational parameters of the high-cell density of an immobilized cell-culture with a complex morphology (such as a pellet or a filamentous fungi) are aeration and efficient culture mixing. When using fluidized bed reactors for the fermentation of a high -viscosity fungal culture, cell -growth prevented efficient mixing by mechanical force to uniformly disperse the substrate between the cells. When the Swingstir ${ }^{\circledR}$ agitator was used in a stirred tank, however, uniform mixing was achieved. To clearly investigate the effect of porous BSPs on enzyme activity, this study used different numbers $(1,500 ; 1,000$; and, 500) and sizes of BSPs in the separated batch cultivations. Here, the activity of alpha amylase from immobilized $A$. oryzae within the BSPs was investigated. The A. oryzae cells were easily immobilized in 
BSPs during batch operation, which allowed examination into the effects on alpha amylase activity, the use of different sizes of immobilized fungi, and the use of different numbers of BSPs.

\section{MATERIAL AND METHODS}

\section{A. Strain and Inoculum Preparation}

For this study we used a wild strain of $A$. oryzae (OSI1013). The fungi were grown in agar plates. Then, the plates were incubated at $30{ }^{\circ} \mathrm{C}$ for $5-6$ days and kept at $4{ }^{\circ} \mathrm{C}$. A spore suspension was prepared by washing the plate in a solution of $0.05 \mathrm{wt} \%$ Tween-80 [Polyoxyethylene (20) Sorbitan monooleate, Wako Co., Kyoto, Japan]. The number of spores was measured using a hemocytometer (Burker Turk) (NanoEnTek Inc., Gyeonggi, Korea). The inoculum of A. oryzae was prepared in $100 \mathrm{~mL}$ Erlenmeyer flasks containing $15.0 \mathrm{~mL}$ of nutrient broth with $1.50 * 10^{7}$ spores $\mathrm{mL}^{-1}$. The cultivation medium in the flasks was composed of seven components (in $\mathrm{g} / 100 \mathrm{~mL}$ ): glucose, 3.0; $\mathrm{KCl}, 0.2$; $\mathrm{KH}_{2} \mathrm{PO}_{4}, 0.1 ; \mathrm{MgSO}_{4}-7 \mathrm{H}_{2} \mathrm{O}, 0.05$; peptone, 1.0 ; and, yeast extract 0.5 . The medium was inoculated with suspended spores. After inoculation, the flasks were incubated for 3 days at $30{ }^{\circ} \mathrm{C}$ and $200 \mathrm{~min}^{-1}$.

\section{B. Fermentation Conditions and Fermenter Structure}

The fermentation experiments were performed in a laboratory- scale, $2.0 \mathrm{~L}$, stirred-tank batch bioreactor (DPC-3A Jar, ABLE BIOTT Co., Tokyo, Japan) with a working volume of $1.5 \mathrm{~L}$, a vessel internal diameter $(\mathrm{H})$ of $0.114 \mathrm{~m}$, a flat bottom, and a fluid height - to - tank diameter ratio of 1.3. Agitation was provided via a Swingstir ${ }^{\circledR}$. In a previous study, [13] the Swingstir ${ }^{\circledR}$ was described as a flexible agitator that would be convenient for the submerged fermentation of $A$. oryzae. The positive hydrodynamic behavior of the Swingstir ${ }^{\circledR}$ was a direct result of its use of un-steady vortices [13].

The Swingstir ${ }^{\circledR}$ is composed made of three blades. The length of each blade is $0.045 \mathrm{~m}$, and the lower and upper widths of the blades are 0.005 and $0.015 \mathrm{~m}$, respectively (Fig. 1). The length of the shaft together with the blade, is $0.161 \mathrm{~m}$ (Fig. 1). Greater details of the Swingstir ${ }^{\circledR}$ design are shown in Fig. 4. In this study, the fermenter was equipped with monitors to control the foam, temperature, $\mathrm{pH}$, agitation rate, torque, and dissolved oxygen (DO). Measurement of the $K_{\mathrm{L}} a$ was based on the recorded DO. In this study, the $K_{\mathrm{L}} a$ was measured using the method mentioned in a previous publication[14]. In this equation, $C^{*}$ and $C_{\mathrm{L}}$ are the saturated and time-dependent DO concentrations in a fermentation culture 1 .

The fermentation medium $(1.5 \mathrm{~L})$ was made up of eight components (in g/100 mL): glucose, 3.0; KCl, 0.2; $\mathrm{KH}_{2} \mathrm{PO}_{4}$, $0.1 ; \mathrm{MgSO}_{4}-7 \mathrm{H}_{2} \mathrm{O}, 0.05$; peptone, 1.0 ; yeast extract, 0.5 (all from Wako Pure Chemical Industries, Osaka, Japan); and, starch 10.0 (Nacalai Tesque, Co., Kyoto, Japan). An external jacket was used to remain the broth temperature at $30^{\circ} \mathrm{C}$. The fermenter was stirred at $250 \mathrm{~min}^{-1}$ for $72 \mathrm{~h}$. The cultivated culture in the stirred tank was sampled, and then it was filtered using a $150 \mathrm{~mL}-20 \mu \mathrm{m}$ bottle-top filter (non-pyrogenic and sterile filter, Corning Inc., California, USA), after which the supernatant was assayed for alpha amylase activity.

The structures of the BSPs were made up of large $(6 * 6 * 3$ $\left.\mathrm{m}^{3}\right)$ and small $\left(6 * 3 * 3 \mathrm{~m}^{3}\right)$ rectangular cubic porous particles
(Fig. 2) of porous polyurethane foam (Bridgestone Co., Ltd. Osaka, Japan) that voids at a rate particle voidage of more than $97 \%$ and has a pore concentration of 50 pores per linear inch. Immobilization was achieved by placing different numbers of $(1,500 ; 1,000$ and, 500) particles inside the fermenter after the medium had been subjected to sterilization.

In this study, the immobilized biomass was measured using a sodium hypochlorite solution, as described in the literature [6].

\section{Glucose concentration, alpha amylase activity assay and immobilized dry cell weight measurement}

The glucose concentration in submerged fluid was determined using a Wako Glucose C2-Test kit (Wako Pure
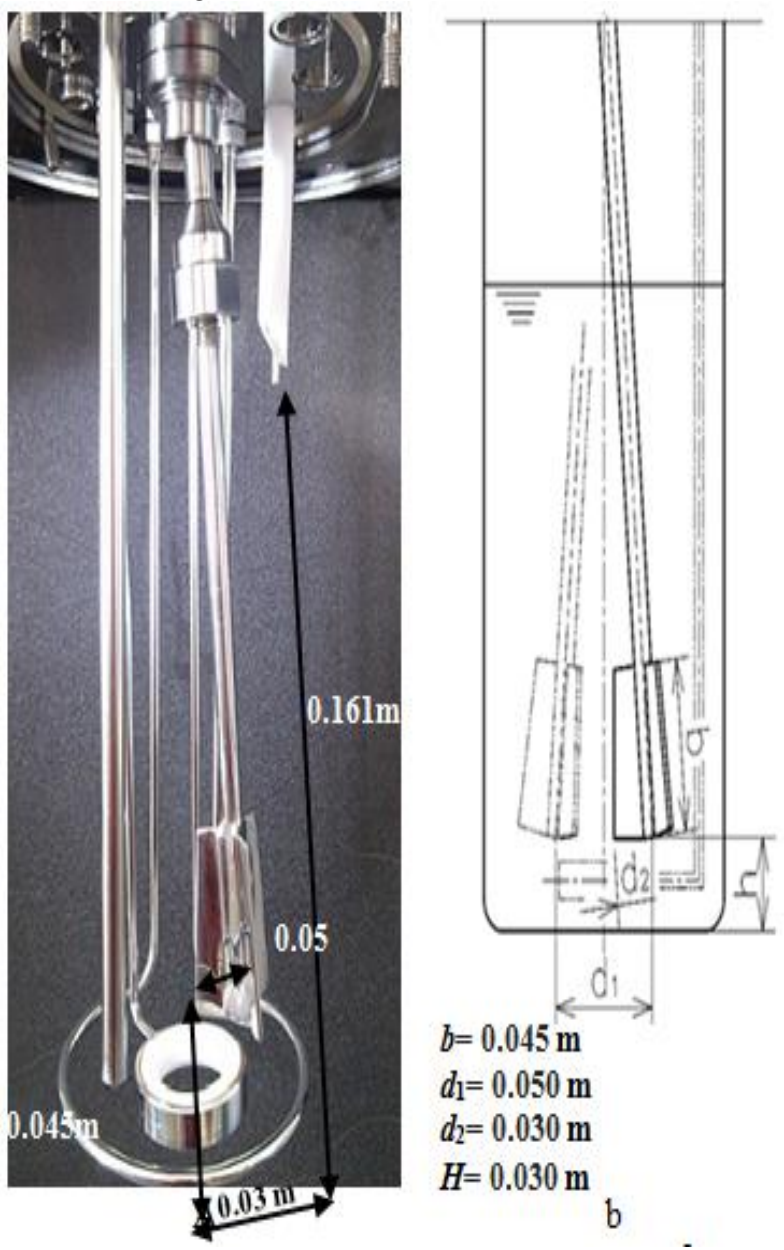

Fig. 1. Illustration of the geometrical design of (a) the Swingstir ${ }^{\circledR}$ used in (b)

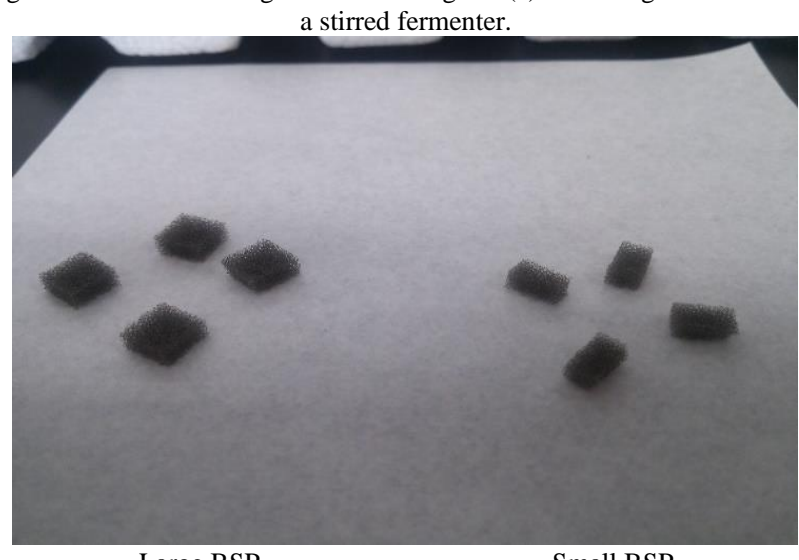

Large BSP

Small BSP

Fig. 2. Schematic of the BSPs used for the immobilized fermentation of A.oryzae. 
Chemical Industries Co., Osaka, Japan). The $20 \mu$ filtered culture samples were poured into $3 \mathrm{~mL}$ portions of -colored reagents and warmed at $37{ }^{\circ} \mathrm{C}$ for $5 \mathrm{~min}$. The absorption at $505 \mathrm{~nm}$ of this solution was measured using a spectrophotometer (MPS-2400, Shimadzu Co., Kyoto, Japan).

Alpha amylase activity was measured for a $1.0 \mathrm{~mL}$ fermentation mixture containing $0.5 \mathrm{~mL}$ of $2.0 \%(\mathrm{w} / \mathrm{v})$ soluble starch in $0.1 \mathrm{M}$ of the phosphate buffer $(\mathrm{pH} 7.0)$ and the enzyme solution. The reactions were performed for various times at $30^{\circ} \mathrm{C}$, and the glucose consumed by the cells was measured with a $\mathrm{C} 2-$ Test kit.

To measure the immobilized biomass, twenty particles were removed and washed with acetone several times to remove substrate-related compounds followed by drying for $3 \mathrm{~h}$ at $70^{\circ} \mathrm{C}$. The dried BSP were weighed and treated with a solution of sodium hypochlorite (approximately $10 \% \mathrm{v} / \mathrm{v}$ ) to separate the biomass. The cleaned particles were rinsed, dried, and re-weighed. Estimates of the biomass were based on the difference between the two obtained weights.

\section{Rheological measurements}

The rheological model of the submerged culture of $A$. oryzae was compatible with the power-law model [15]. Here, rheological study using a HAAKETM viscometer-550 (Thermo scientific, USA) presented the shear-thinning and non-Newtonian behavior of a submerged fluid after cell growth and immobilization. The data were measured according to the Ostwald-de Waele model [the average error for the calculated consistency $(K)$, and flow index $(n)$, which showed that the values had increased by 15 and $4 \%$, respectively]. The obtained values were apparent as the $K$ and $n$ values due to cell adherence and the high-viscosity properties of the fermented fluid. As was mentioned, measurements were performed on the culture without BSPs.

\section{RESULTS AND DISCUSSION}

A. Effect that the size and number of biomass support particles exerts on substrate consumption, alpha-amylase activity and immobilized cells

The results of the glucose concentration in the fermentation medium during each sampling appear in Fig. S1 (supported data). As illustrated in Fig. S1, the highest rate of sugar consumption was in the culture without passive immobilization (control). However, when using the 1,000 and 500-count larges BSPs the sugar consumption rate was low. It could be concluded that one of the advantages of fungal immobilization is the prevention of a high rate of substrate consumption (Table I) during the submerged fermentation. In other words, by increasing the numbers of support particles, the rate of substrate consumption available for growth inside the cells and on the BSPs was increased (Table I).

Moreover, studies have reported that when microorganisms in the fermentation fluid experience shear stress and existing toxic compounds, the enzyme activity of immobilized cells is higher than that of non-immobilized cells [4]. The A. oryzae genomes contain hydrolytic enzyme-encoding genes that play a crucial role in biorefining [15].

Herein, we compare the activity of alpha-amylase during various immobilization experiments. Li et al. [16] previously
TABLE I. EFFECT OF IMMOBILIZATION (SIZE AND NUMBER OF BSPS) ON THE RATE OF GLUCOSE CONSUMPTION IN A SUBMERGED CULTURE.

\begin{tabular}{|c|c|c|}
\hline \multirow{2}{*}{ BSP Size } & BSP $/ 1.5 \mathrm{~L}$ & $\begin{array}{c}\text { Glucose consumption rate } \\
\left(\mathrm{gL}^{-1} \mathrm{~h}^{-1}\right)\end{array}$ \\
\hline \multirow{3}{*}{ Large } & 1500 & 0.32 \\
\cline { 2 - 3 } & 1000 & 0.22 \\
\cline { 2 - 3 } & 500 & 0.21 \\
\hline \multirow{2}{*}{ Small } & 1000 & 0.26 \\
\hline Control & 500 & 0.25 \\
\hline & - & 0.34 \\
\hline
\end{tabular}

confirmed that a large amount of glucoamylase and alpha-amylase activity was obtained in shake flasks in repeated-batch processes using A.niger in the present study, alpha-amylase activity of $A$. oryzae fermentation in a stirred tank using a flexible agitator in an immobilized culture was assessed. The results of enzyme activity in Table II show that in the culture without support particles the initial enzyme activity was the highest, but after one and two days the fermentation activity of non-immobilized cells was decreased. The highest enzyme activity at $t=72 \mathrm{~h}$ was in the culture fermented using 500 large-sized support particles. Comparing the results of alpha amylase activity with immobilized biomass showed that under conditions of highly immobilized cells, the final enzyme activity was higher.

The results of Table III show that in the cell-culture immobilized with 500 large BSPs, the final immobilized amount of biomass was highest. Previous reports described physico-chemical interactions that take place between macroporous carriers that increase the stability of entrapped cells, which in turn [1] could lead to an increase in the fungal biomass. For all experiments performed in this study, when using small 1,000 BSPs the final amount of immobilized biomass was half that produced when using 500 of the larger BSPs (Table III). Therefore, increasing the number of BSPs did not lead to an increase in the amount of when the BSPs were of the smaller variety (Fig. S2). The difference between the non-immobilized samples of biomass during each experiment were not considerable, so that its effect on the fermentation characteristics was not investigated.

Additionally, in this study, during the immobilization of fungi using 1,500 BSPs the immobilized biomass was low due to the consumption of substrate (such as glucose see Table III) for the maintenance of cell viability or multiplication. Furthermore, the optimum growth of A.oryzae occurred in the presence of 500 suspended foam particles in a stirred tank at over the time span of $250 \mathrm{~min}^{-1}$. No effective cell growth was observed with a loading of 1,500 large support particles. In the culture containing small particles, the main reason for the loss of the immobilized cells was the structure of the particles. According to previous publications, [13] the average pellet size of the small-particle cells at $72 \mathrm{~h}$ was approximately $6.5 \mathrm{~mm}$ and the small pellets could not stably adhere with such a small surface area $(3 * 6$ or $3 * 3$

TABLE II. RESULTS OF ALPHA-AMYLASE ACTIVITY (UML ${ }^{-1}$ ) USING BSPS DURING FERMENTATION PER EACH SAMPLING TIME.

\begin{tabular}{|c|c|c|c|}
\hline Sample & $24 \mathrm{~h}$ & $48 \mathrm{~h}$ & $72 \mathrm{~h}$ \\
\hline $1500-\mathrm{L}$ & 2203 & 5449 & 1707 \\
\hline $1000-\mathrm{L}$ & 4104 & 798 & 1354 \\
\hline $500-\mathrm{L}$ & 1800 & 979 & 2702 \\
\hline $1000-\mathrm{S}$ & 1380 & 2085 & 360 \\
\hline $500-\mathrm{S}$ & 545 & 1661 & 1200 \\
\hline Control & 3000 & 2090 & 2000 \\
\hline
\end{tabular}


Effect of Macroporous Support Particles on Cell Immobilization, Mass Transfer and Rheology in a Stirred Cultivation of Aspergillus oryzae Using a Swingstir ${ }^{\circledR}$ Mixer

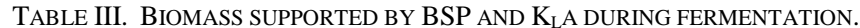

\begin{tabular}{|c|c|c|c|c|c|c|c|c|}
\hline \multirow[t]{2}{*}{ BSP Size } & \multirow{2}{*}{ BSP number $/ 1.5 \mathrm{~L}$} & \multirow[t]{2}{*}{$K_{\mathrm{L}} a\left(\mathrm{~h}^{-1}\right)$} & \multicolumn{3}{|c|}{$\begin{array}{l}\text { Cells immobilized within BSP } \\
\text { [mg/BSP] }\end{array}$} & \multicolumn{3}{|c|}{$\begin{array}{l}\text { Non- immobilized biomass } \\
{[\mathrm{g} / \mathrm{L}]}\end{array}$} \\
\hline & & & $24 \mathrm{~h}$ & $48 \mathrm{~h}$ & $72 \mathrm{~h}$ & $24 \mathrm{~h}$ & $48 \mathrm{~h}$ & $72 \mathrm{~h}$ \\
\hline \multirow{3}{*}{ Large } & 1,500 & 16 & 0.36 & 1.58 & 2.99 & 3.5 & 7.1 & 10 \\
\hline & 1,000 & 27 & 1.82 & 3.70 & 2.50 & 1.9 & 6.0 & 14.0 \\
\hline & 500 & 73 & 0.13 & 8.96 & 11.95 & 2.5 & 3.0 & 8.0 \\
\hline \multirow{2}{*}{ Small } & 1,000 & 48 & 0.20 & 6.60 & 6.00 & 3.0 & 4.0 & 9.5 \\
\hline & 500 & 19 & 2.58 & 5.67 & 2.10 & 1.4 & 4.2 & 11.0 \\
\hline Control & - & 50 & - & - & - & 2.0 & 4.5 & 10.6 \\
\hline S. Hama et al. [6] & $\begin{array}{l}\text { Sakaguchi flasks -100 } \\
\text { ml- } 150 \text { BSP }\end{array}$ & - & 2.53 & 3.47 & 4.55 & - & - & - \\
\hline
\end{tabular}

$\mathrm{mm}^{2}$ ). The decrease in the culture when using 1,000 - large BSPs was obviously neither the number of particles nor the structure, which suggests more study on morphology is needed in the near future to determine the reason.

\section{B. Oxygen mass transfer during the stirred fermentation of immobilized Aspergillus oryzae}

One of the major challenges in immobilized fermentation is complex mass transfer during the substrate penetration of the active cells and also when toxic products are removed from the cultivation culture. Oxygen up take in immobilized cell cultures is an important operational problem to be solved, because oxygen transfer is often the rate-limiting step in a suspension culture, and the phenomenon is even more severe in immobilized cell.

Moreover, the growth of the filamentous fungus increases the viscosity of the medium, which can hinder the mass transfer capabilities of the fermenter. The volumetric oxygen transfer coefficient received the most attention in this study because it they are measures the bioreactor performance. The recorded concentration of the oxygen in the fermentation culture and the $K_{\mathrm{L}} a$ are shown in Table III and Fig. 3, respectively. The results in Table III indicate that increasing the number of large BSP decreased the $K_{\mathrm{L}} a$. The $K_{\mathrm{L}} a$ is increased with increases in the number of small particles because the surface and structure of small BSPs promote better air circulation as the air bubbles are easily broken and carried to improve the air capacity of the culture (compared with the large surface areas of large particles). When the number of large particles was increased, most of the bubbles were trapped inside the porous spaces.

As shown in Fig. 3, the highest oxygen concentration in the growth culture of fungi occurred when using large BSPs (500-count). For this reason, $K_{\mathrm{L}} a$ could be at the optimum value under these conditions. One of the challenges in mass

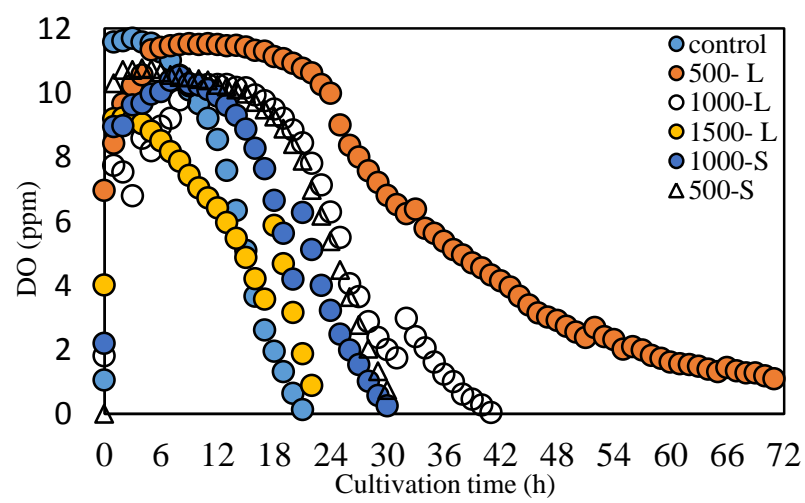

Fig. 3. Recorded concentrations of dissolved oxygen during passive immobilization.

transfer during immobilization is the appearance of dead-mixing zones when the number of support particles is increased. In this study, it was apparent that by increasing the number of BSPs the dead mixing zones (Fig. 4b) in the fermenter were increased and the fermentation system required an increase in power to accomplish perfect particle fluidization.

\section{Studying the rheology of an immobilized submerged culture}

In previous reports, increasing the broth viscosity and strong shear-thinning behavior of fermented fluid was presented a challenge for fungal cultivation [13], [17]. Experimental studies show the power-law model for fermentation fluid even under immobilization conditions.

It was significant that after one of day cultivation the entire immobilized culture was a non-Newtonian fluid with shear-thinning properties that can be expressed by a power-law model (Table IV). The effects of immobilization (size and number of BSPs) on the rheological behavior of the submerged culture are shown in Table IV.

Important conclusions about rheology in the passive immobilization of A.oryzae follow

(a) By decreasing the size of the BSPs, the shear-thinning behavior of the fluid was increased ( $n$ and $K$ were increased). The large $K$ values indicate a high-viscosity culture particularly when immobilization was done using 1,000 small BSPs. This could be the reason of the immobilized biomass and oxygen mass transfer coefficient were decreased when the 500 small BSPs were used in fermentation.

(b) When passive immobilization was performed using 500 large BSPs, the $n$ values during sampling were low and controllable, which indicates that this condition could be

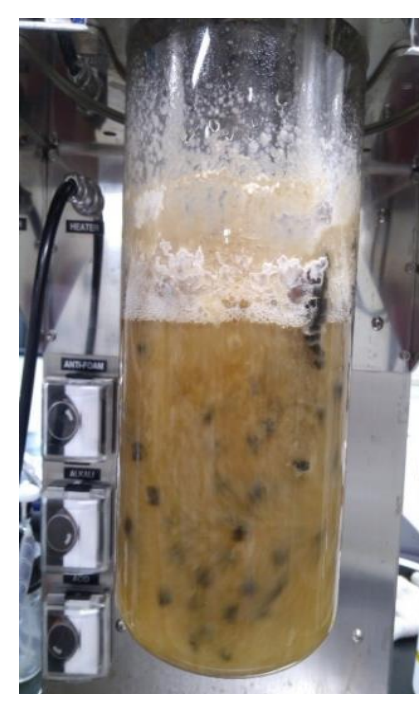

a

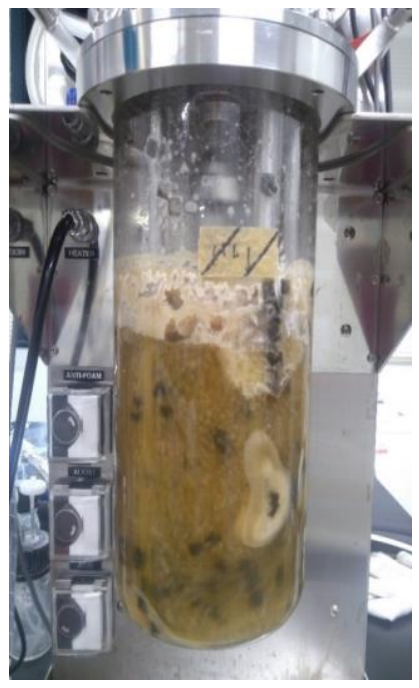

$\mathrm{b}$
Fig. 4. (a) Uniform distribution of 500 large -BSPs at $t=48 \mathrm{~h}$; (b) Preparation of a dead-mixing zone in the tank wall caused by increase in the number of BSPs, (1,000 -large BSPs) at $t=48 \mathrm{~h}$. 
International Journal of Engineering and Applied Sciences (IJEAS)

ISSN: 2394-3661, Volume-5, Issue-10, October 2018

TABLE IV. EFFECT OF IMMOBILIZATION (SIZE AND NUMBER OF BSPS) ON THE RHEOLOGICAL BEHAVIOR OF A SUBMERGED CULTURE.

\begin{tabular}{|c|c|c|c|c|}
\hline \multirow{2}{*}{ BSP Size } & \multirow{2}{*}{ BSP number /1.5 L } & \multicolumn{3}{|c|}{ Rheology parameters of cultivation culture } \\
\cline { 2 - 5 } & & $24 \mathrm{~h}$ & $48 \mathrm{~h}$ & $72 \mathrm{~h}$ \\
\hline \multirow{2}{*}{ Large } & 1500 & - & $n=0.15, K=5.46 \mathrm{Pas}^{\mathrm{n}}$ & $n=0.42, K=0.36 \mathrm{Pas}^{\mathrm{n}}$ \\
& 1000 & $n=0.22, K=7.84 \mathrm{Pas}^{\mathrm{n}}$ & - & $n=0.70, K=1.59 \mathrm{Pas}^{\mathrm{n}}$ \\
& 500 & $n=0.18, K=28.45 \mathrm{Pas}^{\mathrm{n}}$ & $n=0.1, K=25.00 \mathrm{Pas}^{\mathrm{n}}$ & - \\
\hline \multirow{2}{*}{ Small } & 1000 & $n=0.55, K=389 \mathrm{Pas}^{\mathrm{n}}$ & $n=0.44, K=286 \mathrm{Pas}^{\mathrm{n}}$ & $n=0.58, K=166 \mathrm{Pas}^{\mathrm{n}}$ \\
& 500 & $n=0.46, K=106 \mathrm{Pas}^{\mathrm{n}}$ & $n=0.38, K=117 \mathrm{Pas}^{\mathrm{n}}$ & $n=0.23, K=88 \mathrm{Pas}^{\mathrm{n}}$ \\
\hline Control & - & - & $n=0.10, K=8.16 \mathrm{Pas}^{\mathrm{n}}$ & $n=0.26, K=50 \mathrm{Pas}^{\mathrm{n}}$ \\
\hline
\end{tabular}

amenable to an increase in the amount of immobilized biomass because cell growth is promoted in microporous particles. Also, these results confirm the agreement between the results for immobilized biomass (Table II - IV) enzyme activity and rheology.

(c) By changing the fermentation time (from $24 \mathrm{~h}$ to $48 \mathrm{~h}$ ) and decreasing the $K$ regardless of whether and $n$ values when larger BSPs were used, immobilization was increased significantly, with small one, because more cells could be immobilized into the BSP and the complexity of fermentation in a viscous culture was simplified. According to previous findings, with decrease in the $K$ and $n$ of the mechanical stress was decreased on the non-immobilized cells.

(d) In the present study, the $K$ and $n$ values were higher during mixing with smaller BSPs than when using larger BSPs. Increase in the fermentation time, decreased $K$ regardless of whether large or small BSPs were used. Without the use of support particles, however, $K$ was increased, from the first sampling to the end of the fermentation. Previous studies have shown that increasing the broth viscosity makes cultivation a challenge [13], [17]. These results show that utilizing large BSPs could be an easy solution to decreasing the non-Newtonian properties and preventing the obstacles that arise from a high-viscosity cell culture.

(e) One of the challenges to mass transfer during fermentation is the thixotropic behavior of a culture. Therefore, the effect that the use of BSPs can exert on the thixotropic behavior of cultivated was investigated in this study. The viscosity of fermentation culture versus shear rate $\left(\mathrm{s}^{-1}\right)$ was measured (Fig. 5). Recorded data indicate that when using large particles for immobilization, the dependency of the fluid viscosity on fermentation time was higher than when using the small BSPs. Therefore, fermentation cultures agitated using small BSPs were non-Newtonian fluids with a low level of thixotropic behavior.

\section{CONCLUSION}

In this study, immobilization of A.oryzae during stirred-batch fermentation was studying using different sizes and numbers of BSPs. Measurement results showed that the use of BSP exerted important effects on the characteristics of fermentation, which follow.
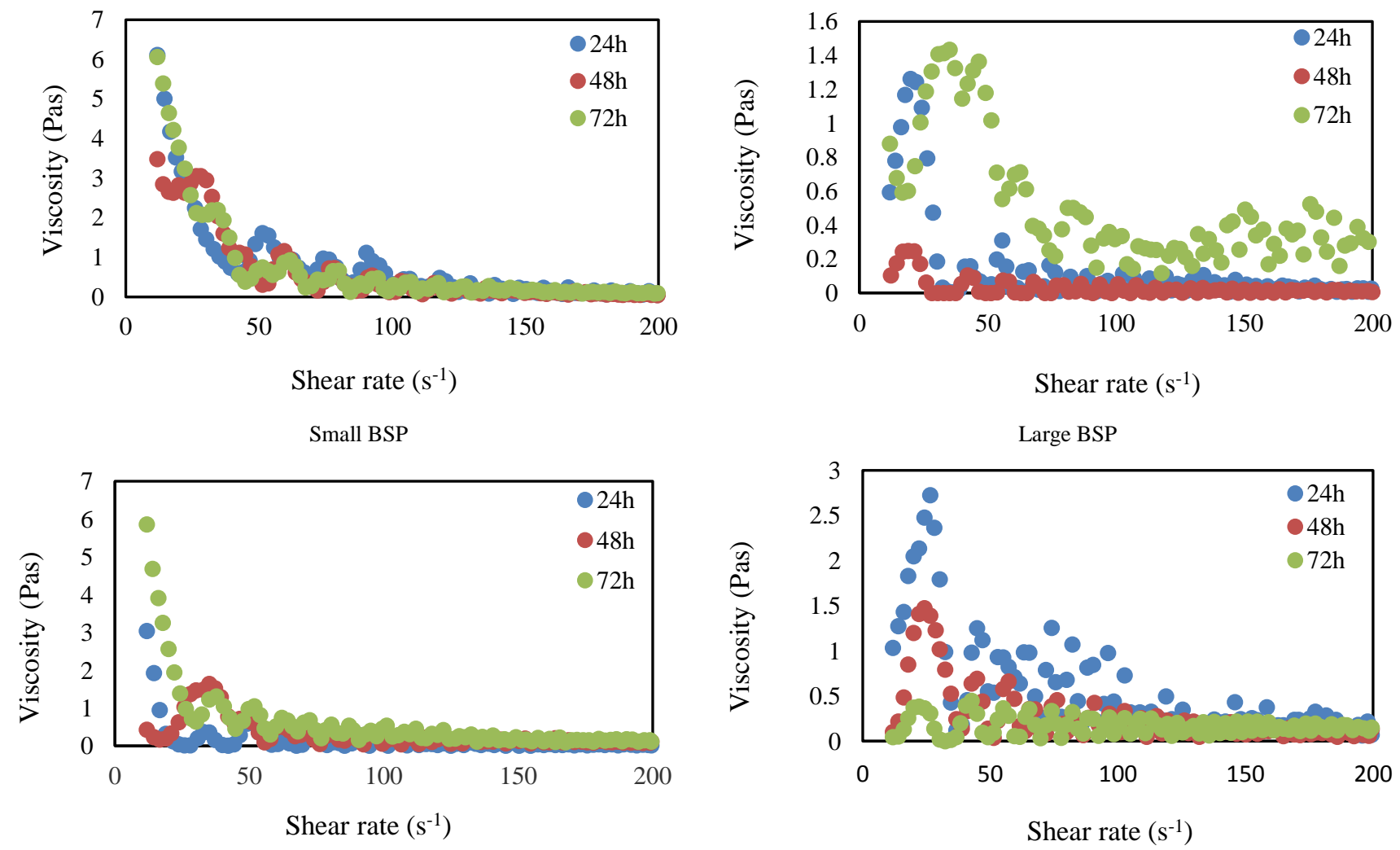

Small BSP

Large BSP

Fig. 5. Effect of microporous particle support (a) 1,000 BSP and (b) 500 BSP on thixotropic property of cultivation culture. 
- One of the advantages of fungal immobilization is the prevention of high rates of glucose consumption during submerged fermentation.

- The final amount of immobilized A.oryzae using 1,000 small-sized BSPs with was half that when using 500 larger BSPs. The use of 500 larger BSPs achieved the largest amount of final immobilized biomass. Comparing the results of alpha amylase activity among the levels of immobilized biomass showed under conditions with a high rate of immobilized cells, the final enzyme activity was also high.

- Dead-mixing zones were created in a tank wall with increases in the numbers of BSPs, which created obstacles to substrate or oxygen transfer.

- Decreases in the size of BSPs increased the shear-thinning behavior of fluids ( $n$ and $K$ were increased). When larger particles were used, a greater number of cells could be immobilized into the BSPs, and the complexity of fermentation in a viscous culture was improved. When using the larger particles for immobilization cell-culture viscosity showed a greater dependency on fermentation time.

\section{SUPPORTING DATA}

Using the results of Figs. S1 and S2, the relation between structure or number of BSP and glucose used for growing the immobilized and non-immobilized cells could be investigated. In the control experiment (non-immobilized culture), the glucose concentration in fermentation culture was lower than that of the other immobilized experiment. At relatively same non-immobilized biomass concentration, by

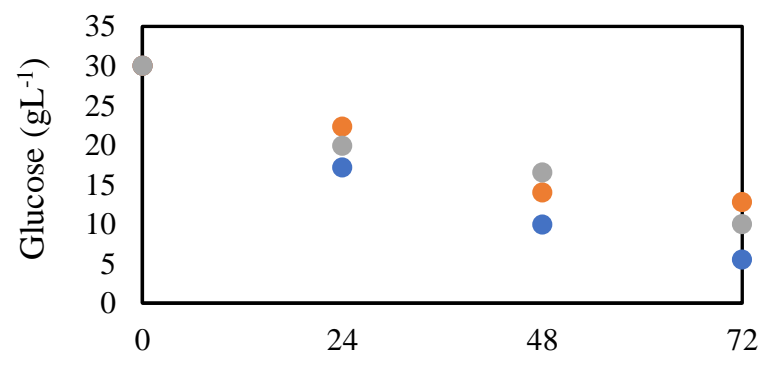

Sampling time (h)

o control 500- Small 1000-Small

Fig. S1-a. Glucose concentration in fermentation culture in each sampling.

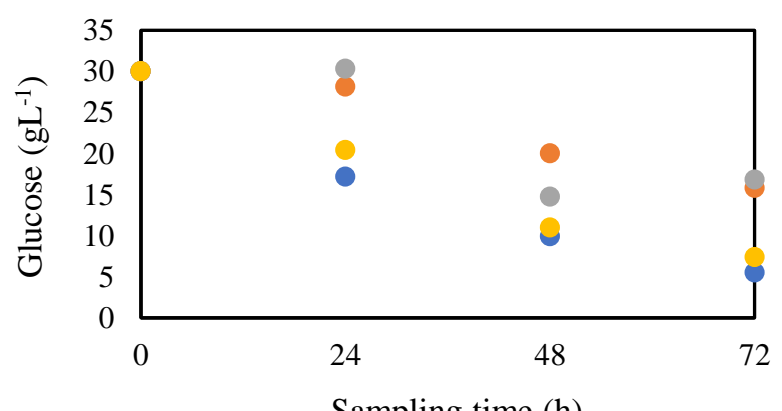

- control 500- Large 1000- Large $\bigcirc 1500-$ Large

Fig. S1-b. Glucose concentration in fermentation culture in each sampling.

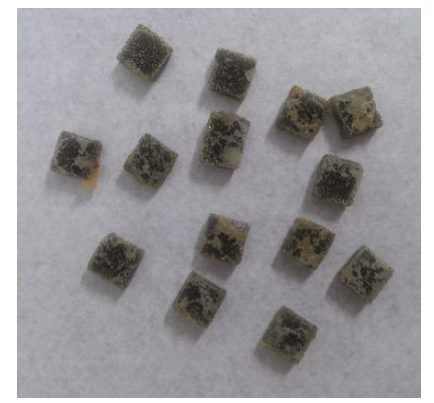

a

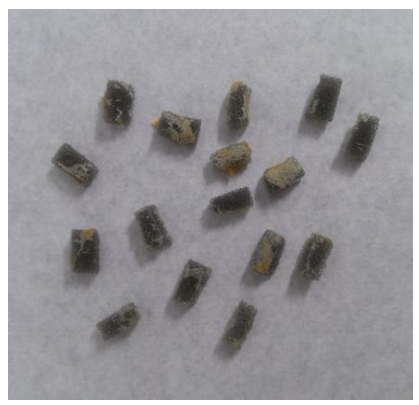

b
Fig. S2. Scheme representation of A.oryzae immobilized in BSP at $\mathrm{t}=72 \mathrm{~h}$ in the culture with (a) 1,000-large BSP and (b) 1,000-small BSP.

increasing the number of large particles, the glucose concentration in the cultivation medium was decreased.

Above scheme shows immobilization of A. oryzae inside and on the surface of porous particles in the culture with 1,000-large BSPs and 1,000-small BSPs.

\section{ACKNOWLEDGEMENTS}

This work was supported by the Special Coordination Funds for Promoting Science and Technology, the Creation of Innovation Centers for Advanced Interdisciplinary Research

Areas (Innovative Bioproduction Kobe) from Ministry of Education, Culture, Sports, Science and Technology (MEXT), Japan.

\section{REFERENCES}

[1] F. Federici, "Potential applications of viable, immobilized fungal cell systems," World J. Microbiol. Biotechnol., vol. 9, no. 5, pp. 495-502, 1993.

[2] S. Rodríguez Couto, "Dye removal by immobilised fungi," Biotechnol. Adv., vol. 27, no. 3, pp. 227-235, 2009.

[3] D. Gao, L. Du, J. Yang, W.-M. Wu, and H. Liang, "A critical review of the application of white rot fungus to environmental pollution control.," Crit. Rev. Biotechnol., vol. 30, no. 1, pp. 7077, Mar. 2010.

[4] E. Bardone et al., "Biological treatment of industrial wastewaters: a fungal approach," 2012.

[5] A. B., B. G. M., L. P. J. S., and P. A., "Biological particles of given size, shape, and density for use in biological reactors," Biotechnol. Bioeng., vol. 21, no. 2, pp. 193-200, Jun. 2018.

[6] K. Ban, M. Kaieda, T. Matsumoto, A. Kondo, and H. Fukuda, "Whole cell biocatalyst for biodiesel fuel production utilizing Rhizopus oryzae cells immobilized within biomass support particles," Biochem. Eng. J., vol. 8, no. 1, pp. 39-43, 2001.

T. Nakashima, H. Fukuda, S. Kyotani, and H. Morikawa, "Culture conditions for intracellular lipase production by Rhizopus chinensis and its immobilization within biomass support particles," J. Ferment. Technol., vol. 66, no. 4, pp. 441-448, 1988. . Driouch, R. Hansch, T. Wucherpfennig, R. Krull, and C. Wittmann, "Improved enzyme production by bio-pellets of Aspergillus niger: targeted morphology engineering using titanate microparticles.," Biotechnol. Bioeng., vol. 109, no. 2, pp. 462471, Feb. 2012.

[9] H. Driouch, B. Sommer, and C. Wittmann, "Morphology engineering of Aspergillus niger for improved enzyme production.," Biotechnol. Bioeng., vol. 105, no. 6, pp. 1058-1068, Apr. 2010.

[10] B.-A. Kaup, K. Ehrich, M. Pescheck, and J. Schrader, "Microparticle-enhanced cultivation of filamentous microorganisms: increased chloroperoxidase formation by Caldariomyces fumago as an example.," Biotechnol. Bioeng., vol. 99, no. 3, pp. 491-498, Feb. 2008.

[11] K. A. Lusta, I. K. Chung, I. W. Sul, H. S. Park, and D. I. Shin, 
"Immobilization of fungus Aspergillus sp. by a novel cryogel technique for production of extracellular hydrolytic enzymes," Process Biochem., vol. 35, no. 10, pp. 1177-1182, 2000.

[12] S. Hama, K. Onodera, A. Yoshida, H. Noda, and A. Kondo, "Improved production of phospholipase A1 by recombinant Aspergillus oryzae through immobilization to control the fungal morphology under nutrient-limited conditions," Biochem. Eng. J., vol. 96, pp. 1-6, 2015.

[13] N. Ghobadi, C. Ogino, T. Ogawa, and N. Ohmura, "Using a flexible shaft agitator to enhance the rheology of a complex fungal fermentation culture.," Bioprocess Biosyst. Eng., vol. 39, no. 11, pp. 1793-1801, Nov. 2016.

[14] N. Ghobadi, C. Ogino, T. Ogawa, and N. Ohmura, "Mixing characteristics of submerged fungal fluid in a flexible stirred mixer system," J. Chem. Eng. JAPAN, vol. 51, no. 2, pp. 143-151, 2018.

[15] T. Kobayashi et al., "Genomics of Aspergillus oryzae.," Biosci. Biotechnol. Biochem., vol. 71, no. 3, pp. 646-670, Mar. 2007.

[16] G.-X. Li, Y.-Y. Linko, and P. Linko, "Glucoamylase and $\alpha$-amylase production by immobilized Aspergillus niger," Biotechnol. Lett., vol. 6, no. 10, pp. 645-650, 1984.

[17] N. Ghobadi, C. Ogino, K. Yamabe, and N. Ohmura, "Characterizations of the submerged fermentation of Aspergillus oryzae using a Fullzone impeller in a stirred tank bioreactor.," $J$. Biosci. Bioeng., vol. 123, no. 1, pp. 101-108, Jan. 2017. 